\title{
Design the Conceptual Model of Teleconsultation System for Dental Diseases
}

\section{Fateme Moghbeli1 ${ }^{(\mathbb{D}}$, Mostafa Langarizadeh ${ }^{2}{ }^{(D}$, Yashil Ahadi Moghadam ${ }^{3}$, Susan Hasanpour Heidari ${ }^{4}$}

${ }^{1} \mathrm{PhD}$ in Medical Informatics, Department of Health Information Management, School of Health Management and Information Sciences, Iran University of Medical Sciences, Tehran, Iran.

2Department of Health Information Management, School of Health Management and Information Sciences, Iran University of Medical Sciences, Tehran, Iran.

${ }^{3}$ Doctor of Dentistry, School of Dentistry, Shahid Beheshti University of Medical Sciences, Tehran, Iran.

${ }^{4} \mathrm{MSc}$ in Medical Informatics, Department of Health Information Management, School of Health Management and Information Sciences, Iran University of Medical Sciences, Tehran, Iran

\begin{tabular}{ll}
\hline Article Info & A B S T R A C T \\
\hline $\begin{array}{l}\text { Article type: } \\
\text { Research }\end{array}$ & Introduction: \\
\hline Article History: & Worldwide, people living in rural and remote area with the lack of access to \\
Received: $2019-09-08$ & medical care are vulnerable. Despite of improvement in dentistry, dental \\
Revised: - & caries is still one of the prevalent problems among people. By using tele- \\
Accepted: $2019-09-20$ & dentistry and transforming electronic patient information, dental services \\
& can be delivered specially in remote area so leads to improve public dental \\
& health.
\end{tabular}

\section{* Corresponding author:}

Susan Hasanpour Heidari

MSc in Medical Informatics, Department of Health Information

Management, School of Health

Management and Information

Sciences, Iran University of Medical

Sciences, Tehran, Iran.

Email: susan.hasanpour@gmail.com

\section{Methods:}

This is an applied development study and 24 dentists and dental radiologists were participated in this survey. The questionnaire was filled out by participant to obtain information about requirement for designing the conceptual model for tele-consultation system for dental problems. Collected data was analyzed by descriptive statics with SPSS version 22 software.

\section{Results:}

According to results patient name and last name, gender, emergency level, sign of the problem, patient history in patient demographic and clinical information section and in system capabilities section, dedicate the space for dentist to diagnosis and the space for seeing diagnosis report by patient was the 100 percent requirement considered. After requirement analysis conceptual model as use case diagram was designed.

\section{Conclusion:}

According to results, using tele-dentistry can improve relationship between specialists and patients without considering the distance and eventually improve public oral health in society.

Keywords:

Telemedicine, Tele-dentistry, Conceptual design

\section{How to cite this paper}

Moghbeli F, Langarizadeh M, Ahadi Moghadam Y, Hasanpour Heidari S. Design the Conceptual Model of Teleconsultation System for Dental Diseases. Front Health Inform. 2019; 8(1): e22. DOI: 10.30699/fhi.v8i1.205

\section{INTRODUCTION}

Telemedicine in the definition of the World Health Organization means the provision of health care services when distance is an important factor in telemedicine health providers using ICT to transmit the correct information in order to Diagnosis, treatment, and even use in areas for evaluation and education that ultimately lead to improved individual health in the community [1]
Telemedicine as a new way of providing health care services, regardless of geographical distances, plays an important role in improving the health of people living in remote areas [2] . People living in rural and remote areas around the world are experiencing problems in accessing quality health care in a timely manner because specialist physicians are usually present in places where the urban population is concentrated. Telemedicine is a solution to bridge the gap between individuals in accessing health care services []ㅡ. Telemedicine refers to the application 
of communication technologies in the electronic transmission of a variety of textual, audio, and visual data, including still and moving images. According to the American Medical Colleges Association, these technologies play an important role in supporting health care by overcoming geographical distances between physician and patient $[\underline{4}, \underline{5}]$. Telemedicine services include a wide range of medical activities including diagnosis, treatment, monitoring. Prevention, continuous education of health care providers and consumers, and research and evaluation [ $[\underline{6}, \underline{7}]$. Due to advances in dentistry and improved dental health since the early 21 st century, dental caries is still one of the most common chronic diseases among children and adults worldwide, causing tooth loss. Tooth decay can cause severe pain, infection, and even death [요, $\underline{9}]$. Advances in oral care show that rapid diagnosis, preventive treatment, and timely intervention can prevent the development of oral diseases. Any delay in treatment can lead to dental pain, tooth decay, and ultimately unpleasant side effects. Unfortunately, many children and adults suffering from oral diseases are denied regular access to a dental clinic for various reasons, such as economic, geographical and even ethnological issues. In many rural areas, problems such as remote access, population dispersal, climatic differences and road problems, lack of public transport, make it difficult to establish an oral health care center $[\underline{10}, \underline{11}]$.

According to the World Health Organization, the ratio of the number of dentists to the total population in Iran in 1991 is one dentist per 3,000, while the ratio is one for every 1,700 in developed countries such as the United States. However, important factors such as the level of culture and education, per capita income, place of residence and so on are influential in this respect. Statistics also show that more than 60 percent of Iranian provinces have less than 500 dentists and most dentists and specialists reside in major cities of the country [10].

The primary role of telemedicine is to bridge the gap between the increasing demands for oral health with available resources. The number of specialists in the field of dentistry is lower than the rest of the medical field, so the low proportion of dentists to the general population is particularly worrying, especially in developing countries $[\underline{3}, \underline{12}]$. Remote dental services can be provided using the Internet. These services can be in the form of remote consultations that are conducted directly between the patient and the specialist or indirectly between the different specialists. Using telemedicine technology and removing time and space constraints improves the efficiency and effectiveness of health care services, especially in dentistry $[\underline{2}, \underline{13}]$.

The process of teleconferencing is done either in the form of sending and sending or video conferencing.
In the storage and sending method, data on clinical oral examinations, including digital and radiographic images, are stored electronically and sent to the appropriate physician. It is possible to retrieve and review this data with the relevant physician and to send it to another physician for consultation. In contrast to video conferencing or concurrent counseling, communication between the patient and the physician through communication technology is real-time [14, 15]. Remote dentistry not only enhances access to oral health services, reduces the cost of health care, increases productivity, better management and increases patient referrals, but also uses this technology to bridge the gap between rural and oral health. Destroyed a city and provided oral health services to the farthest reaches of the globe [16].

Given the widespread use of ICT in this field, telemedicine can be considered a good alternative to oral examinations. These services can be performed simultaneously using video conferencing or asynchronous storage and sending for remote consultation or remote detection. Therefore, using this technology in the field of dentistry improves oral health and access to care for the growing population, which reduces costs and reduces dental shortages [17]. In some cases, patients may postpone their visit to a doctor because of financial problems, which may lead to the outbreak. In fact, using this technology can be consulted with specialists to meet the medical needs. Therefore, the waiting time is reduced and in some diseases, it reduces pain as well as the cost to patients []]. Telemedicine provides early diagnosis, facilitation of early treatment of oral diseases, reduced isolation of physicians and their relationship with colleagues and consultation with specialists over the Internet and increased access to care, thus enhancing the quality of life for early detection and follow-up. In general, telemedicine can eliminate inequalities in the provision of oral health care. People in remote and rural areas are in dire need of health care due to a lack of clinical infrastructure and financial problems. Remote dentistry can eliminate the gap in the provision of health care $[\underline{12}, \underline{14}]$. Given the aforementioned cases, it can be said that despite the high number of dental diseases and the problems that patients face in accessing physicians and there is a shortage of relevant specialists in the area of living, including people living in remote areas, and telemedicine can be a good solution to diagnose and even treat some oral diseases. Dental technology can overcome problems such as referrals. They found the need for long distances, unnecessary costs, and the prevalence of the disease unnecessary. In this study, we attempted to collect early data and design a conceptual model of telemedicine system using Unified Modeling Language to help in early diagnosis of oral and dental diseases as well as in the absence 
of Unnecessary visits to the dentist and ultimately to the improvement of the oral health in the community. Using this system in Iran can not only overcome the above mentioned problems but also increase the efficiency of dental science.

\section{MATERIAL AND METHODS}

This was a cross-sectional developmental-applied research conducted in the last three months of 2015. The study population consisted of dentists and radiologists at a dental clinic and dental radiology center in northeast of Tehran. All dentists and radiologists working in the dental clinic, including 15 dentists and 9 dental radiologists, were selected through census sampling. Data collection was done by distribution of questionnaires in person. The questionnaire was developed based on a library study [11, 13]. Which included four sections on demographic and clinical characteristics of the patient, information required by the dentist and radiologist, and system requirements. In the questionnaire, the research community was asked to select the items based on their necessity (one point) or unnecessary (zero points). The face validity of the questionnaire was assessed by the Committee of Experts and the reliability was assessed by testretest method.
The questionnaire was administered to 24 matched groups twice in 15 days' interval. The correlation coefficient was calculated $r=0.8$ and the reliability of the questionnaire was confirmed. Data were analyzed using descriptive statistics and frequency distribution in SPSS software version 22. In this section, each of the required data items was considered as essential only if an average of $60 \%$ of the respondents identified it as essential. At the conceptual design stage, the diagrams were plotted using Visual Paradigm software.

\section{RESULTS}

According to the data collected from 24 dentists and radiologists, $37.5 \%$ of the participants were radiologists and $62.5 \%$ were dentists. $66.6 \%$ of the participants were female and $33.33 \%$ were male. Most of the age group (75\%) belonged to the age group under 35 and most of the subjects (66\%) had work experience under eight years.

In the patient demographic information section, the survey participants indicated the highest percentage of need for name and gender and the least need for items such as race and weight. Table 1 shows the frequency distribution of dentists' and radiologists' responses to the need for data items needed in patients' identity information.

Table 1: Frequency of the required data elements in patient identity information

\begin{tabular}{|c|c|c|c|c|c|c|c|c|c|c|}
\hline \multirow{2}{*}{$\begin{array}{l}\overline{0} \\
\dot{\alpha}\end{array}$} & \multirow{2}{*}{ Variable } & \multirow{2}{*}{ Participants } & \multicolumn{3}{|c|}{ Necessary } & \multicolumn{3}{|c|}{ Unnecessary } & \multicolumn{2}{|c|}{ Total } \\
\hline & & & $\mathrm{n}$ & $\%$ & Mean & $\mathrm{n}$ & $\%$ & Mean & $\mathrm{n}$ & $\%$ \\
\hline \multirow[t]{2}{*}{1} & \multirow[t]{2}{*}{ Name } & Dentist & 15 & 100 & 100 & 0 & 0 & 0 & 15 & 100 \\
\hline & & Radiologist & 9 & 100 & & 0 & 0 & & 9 & 100 \\
\hline \multirow[t]{2}{*}{2} & \multirow[t]{2}{*}{ Last name } & Dentist & 15 & 100 & 100 & 0 & 0 & 0 & 15 & 100 \\
\hline & & Radiologist & 9 & 100 & & 0 & 0 & & 9 & 100 \\
\hline \multirow[t]{2}{*}{3} & \multirow[t]{2}{*}{ Zip code } & Dentist & 10 & 66.7 & 66.7 & 5 & 33.3 & 33.3 & 15 & 100 \\
\hline & & Radiologist & 6 & 66.7 & & 3 & 33.3 & & 9 & 100 \\
\hline \multirow[t]{2}{*}{4} & \multirow[t]{2}{*}{ Age } & Dentist & 14 & 93.3 & 83.3 & 1 & 6.7 & 16.7 & 15 & 100 \\
\hline & & Radiologist & 6 & 66.7 & & 3 & 33.3 & & 9 & 100 \\
\hline \multirow[t]{2}{*}{5} & \multirow[t]{2}{*}{ Gender } & Dentist & 15 & 100 & 100 & 0 & 0 & 0 & 15 & 100 \\
\hline & & Radiologist & 9 & 100 & & 0 & 0 & & 9 & 100 \\
\hline \multirow[t]{2}{*}{6} & \multirow[t]{2}{*}{ Race } & Dentist & 0 & 0 & 0 & 15 & 100 & 100 & 15 & 100 \\
\hline & & Radiologist & 0 & 0 & & 9 & 100 & & 9 & 100 \\
\hline \multirow[t]{2}{*}{7} & \multirow[t]{2}{*}{ Weight } & Dentist & 0 & 0 & 1 & 15 & 100 & 100 & 15 & 100 \\
\hline & & Radiologist & 0 & 0 & & 9 & 100 & & 9 & 100 \\
\hline \multirow[t]{2}{*}{8} & \multirow[t]{2}{*}{ Patients' address } & Dentist & 9 & 60 & 62.5 & 6 & 40 & 37.5 & 15 & 100 \\
\hline & & Radiologist & 5 & 55.5 & & 4 & 44.4 & & 9 & 100 \\
\hline \multirow[t]{2}{*}{9} & \multirow{2}{*}{$\begin{array}{l}\text { Patients' phone } \\
\text { number }\end{array}$} & Dentist & 14 & 93.3 & 64.7 & 1 & 6.7 & 35.3 & 15 & 100 \\
\hline & & Radiologist & 5 & 55.6 & & 4 & 44.4 & & 9 & 100 \\
\hline
\end{tabular}


With regard to radiologist and dentist information (Table 2), the highest percentage of requirements for the name and surname of the dentist and radiologist were highest and the medical system number of the workplace address and radiologist's contact number (less than 30\%) were the least required in the system.

In terms of patient clinical information, such as urgency, current disease symptoms, history of previous illnesses, and 100\% medications each were considered as the main items in the system, as described in Table 3. Finally, in this section, the majority of dentists and radiologists participating in the study believed that all of the data.

In the last section (Table 4), the most necessary and the most unnecessary statistical capabilities of the system were identified for system requirements, image and space loading capability for final dentist insertion and statistical reporting capability.

Table 2: Frequency of User Responses to the Need for Data Elements Required for Dentist and Radiologist Information

\begin{tabular}{|c|c|c|c|c|c|c|c|c|c|c|c|}
\hline \multirow{2}{*}{$\overrightarrow{0}$} & \multirow{2}{*}{\multicolumn{2}{|c|}{ Variables }} & \multirow{2}{*}{ Participants } & \multicolumn{2}{|c|}{ Necessary } & \multicolumn{2}{|c|}{ Unnecessary } & \multicolumn{2}{|c|}{ Total } & \multicolumn{2}{|c|}{ Average } \\
\hline & & & & $\mathrm{n}$ & $\%$ & $\mathrm{n}$ & $\%$ & $\mathrm{n}$ & $\%$ & Necessary & Unnecessary \\
\hline \multirow{2}{*}{1} & \multirow{10}{*}{ 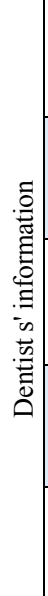 } & \multirow{2}{*}{ Name } & Dentist & 13 & 86.7 & 2 & 13.3 & 15 & 100 & \multirow{2}{*}{83.3} & \multirow{2}{*}{16.7} \\
\hline & & & Radiologist & 7 & 77.8 & 2 & 22.2 & 9 & 100 & & \\
\hline \multirow{2}{*}{2} & & \multirow{2}{*}{ Last name } & Dentist & 12 & 80 & 3 & 20 & 15 & 100 & \multirow{2}{*}{79.2} & \multirow{2}{*}{20.8} \\
\hline & & & Radiologist & 7 & 77.8 & 2 & 22.2 & 9 & 100 & & \\
\hline \multirow{2}{*}{3} & & \multirow{2}{*}{$\begin{array}{l}\text { Medical } \\
\text { System } \\
\text { Number }\end{array}$} & Dentist & 4 & 26.7 & 11 & 73.3 & 15 & 100 & \multirow{2}{*}{41.7} & \multirow{2}{*}{58.3} \\
\hline & & & Radiologist & 6 & 66.7 & 3 & 33.3 & 9 & 100 & & \\
\hline \multirow{2}{*}{4} & & \multirow{2}{*}{$\begin{array}{l}\text { Work } \\
\text { address }\end{array}$} & Dentist & 10 & 66.7 & 5 & 33.3 & 15 & 100 & \multirow{2}{*}{66.7} & \multirow{2}{*}{33.3} \\
\hline & & & Radiologist & 6 & 66.7 & 3 & 33.3 & 9 & 100 & & \\
\hline \multirow{2}{*}{5} & & \multirow{2}{*}{$\begin{array}{l}\text { Telephone } \\
\text { number }\end{array}$} & Dentist & 10 & 66.7 & 5 & 33.3 & 15 & 100 & \multirow{2}{*}{66.7} & \multirow{2}{*}{33.3} \\
\hline & & & Radiologist & 6 & 66.7 & 3 & 33.3 & 9 & 100 & & \\
\hline \multirow{2}{*}{6} & \multirow{10}{*}{ 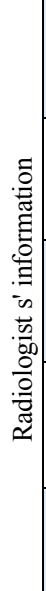 } & \multirow{2}{*}{ Name } & Dentist & 12 & 80 & 3 & 20 & 15 & 100 & \multirow{2}{*}{79.2} & \\
\hline & & & Radiologist & 7 & 77.8 & 2 & 22.2 & 9 & 100 & & \\
\hline & & & Dentist & 12 & 80 & 3 & 20 & 15 & 100 & & \\
\hline & & & Radiologist & 7 & 77.8 & 2 & 22.2 & 9 & 100 & & \\
\hline & & Medical & Dentist & 12 & 80 & 3 & 20 & 15 & 100 & & \\
\hline & & Number & Radiologist & 2 & 22.2 & 7 & 77.8 & 9 & 100 & 10.1 & 05.3 \\
\hline & & Work & Dentist & 3 & 20 & 12 & 80 & 15 & 100 & & \\
\hline 3 & & address & Radiologist & 2 & 22.2 & 7 & 77.8 & 9 & 100 & & \\
\hline 1 & & Telenhone & Dentist & 3 & 20 & 12 & 80 & 15 & 100 & & \\
\hline 0 & & number & Radiologist & 3 & 33.3 & 6 & 66.7 & 9 & 100 & & \\
\hline
\end{tabular}


Table 3: Frequency of responses of dentists and radiologists to data items needed in the clinical information section of patients

\begin{tabular}{|c|c|c|c|c|c|c|c|c|c|c|}
\hline \multirow{2}{*}{ 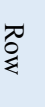 } & \multirow{2}{*}{ Variables } & \multirow{2}{*}{ Participants } & \multicolumn{2}{|c|}{ Necessary } & \multicolumn{2}{|c|}{ Unnecessary } & \multicolumn{2}{|c|}{ Total } & \multicolumn{2}{|c|}{ Average } \\
\hline & & & $\mathrm{n}$ & $\%$ & $\mathrm{n}$ & $\%$ & $\mathrm{n}$ & $\%$ & Necessary & Unnecessary \\
\hline \multirow{2}{*}{1} & \multirow{2}{*}{$\begin{array}{l}\text { Emergency rate (emergency or } \\
\text { non-emergency) }\end{array}$} & Dentist & 15 & 100 & 0 & 0 & 15 & 100 & \multirow{2}{*}{100} & \multirow{2}{*}{0} \\
\hline & & Radiologist & 9 & 100 & 0 & 0 & 9 & 100 & & \\
\hline \multirow{2}{*}{2} & \multirow{2}{*}{ Symptoms of current illness } & Dentist & 15 & 100 & 0 & 0 & 15 & 100 & \multirow{2}{*}{100} & \multirow{2}{*}{0} \\
\hline & & Radiologist & 9 & 100 & 0 & 0 & 9 & 100 & & \\
\hline \multirow{2}{*}{3} & \multirow{2}{*}{ History of previous diseases } & Dentist & 15 & 100 & 0 & 0 & 15 & 100 & \multirow{2}{*}{100} & \multirow{2}{*}{0} \\
\hline & & Radiologist & 9 & 100 & 0 & 0 & 9 & 100 & & \\
\hline \multirow{2}{*}{4} & \multirow{2}{*}{ Taking medicines } & Dentist & 15 & 100 & 0 & 0 & 15 & 100 & \multirow{2}{*}{100} & \multirow{2}{*}{0} \\
\hline & & Radiologist & 9 & 100 & 0 & 0 & 9 & 100 & & \\
\hline \multirow{2}{*}{5} & \multirow{2}{*}{ Radiographic Image (OPG) } & Dentist & 10 & 66.7 & 5 & 33.3 & 15 & 100 & \multirow{2}{*}{58.3} & \multirow{2}{*}{41.7} \\
\hline & & Radiologist & 4 & 44.4 & 5 & 55.6 & 9 & 100 & & \\
\hline \multirow{2}{*}{6} & \multirow{2}{*}{ Color image of the teeth } & Dentist & 11 & 73.3 & 4 & 26.7 & 15 & 100 & \multirow{2}{*}{62.5} & \multirow{2}{*}{37.5} \\
\hline & & Radiologist & 4 & 44.4 & 5 & 55.6 & 9 & 100 & & \\
\hline \multirow{2}{*}{7} & \multirow{2}{*}{$\begin{array}{l}\text { Primary diagnosis of the } \\
\text { dentist }\end{array}$} & Dentist & 13 & 86.7 & 2 & 13.3 & 15 & 100 & \multirow{2}{*}{70.8} & \multirow{2}{*}{29.2} \\
\hline & & Radiologist & 4 & 44.4 & 6 & 55.6 & 9 & 100 & & \\
\hline & Reason for patient referral and & Dentist & 14 & 93.3 & 1 & 6.7 & 15 & 100 & 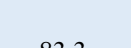 & 16 \\
\hline 0 & complaint & Radiologist & 6 & 66.7 & 3 & 33.3 & 9 & 100 & 05.5 & 10.1 \\
\hline
\end{tabular}

Table 4: Frequency of Responses of Researchers to the Need for System Capabilities

\begin{tabular}{|c|c|c|c|c|c|c|c|c|c|c|}
\hline \multirow{2}{*}{$\begin{array}{l}\pi \\
\Sigma \\
\Sigma\end{array}$} & \multirow{2}{*}{ Variables } & \multirow{2}{*}{ Participants } & \multicolumn{2}{|c|}{ Necessary } & \multicolumn{2}{|c|}{ Unnecessary } & \multicolumn{2}{|c|}{ Total } & \multicolumn{2}{|c|}{ Average } \\
\hline & & & $\mathrm{n}$ & $\%$ & $\mathrm{n}$ & $\%$ & $\mathrm{n}$ & $\%$ & Necessary & Unnecessary \\
\hline \multirow{2}{*}{1} & \multirow{2}{*}{ Ability to upload images } & Dentist & 13 & 86.7 & 2 & 13.3 & 15 & 100 & \multirow{2}{*}{87.5} & \multirow{2}{*}{12.5} \\
\hline & & Radiologist & 8 & 88.9 & 1 & 11.1 & 9 & 100 & & \\
\hline \multirow{2}{*}{2} & \multirow{2}{*}{ Ability to delete images } & Dentist & 14 & 93.3 & 1 & 6.7 & 15 & 100 & \multirow{2}{*}{87.6} & \multirow{2}{*}{12.5} \\
\hline & & Radiologist & 7 & 77.8 & 2 & 22.2 & 9 & 100 & & \\
\hline \multirow{2}{*}{3} & \multirow{2}{*}{$\begin{array}{l}\text { A place for radiologists to } \\
\text { record explanations }\end{array}$} & Dentist & 14 & 93.3 & 1 & 6.7 & 15 & 100 & \multirow{2}{*}{91.7} & \multirow{2}{*}{8.3} \\
\hline & & Radiologist & 8 & 88.9 & 1 & 11.1 & 9 & 100 & & \\
\hline \multirow{2}{*}{4} & \multirow{2}{*}{$\begin{array}{l}\text { An option to declare the need } \\
\text { for an in-patient examination }\end{array}$} & Dentist & 14 & 93.3 & 1 & 6.7 & 15 & 100 & \multirow{2}{*}{83.3} & \multirow{2}{*}{16.7} \\
\hline & & Radiologist & 6 & 66.7 & 3 & 33.3 & 9 & 100 & & \\
\hline \multirow{2}{*}{5} & \multirow{2}{*}{$\begin{array}{l}\text { A space for the dentist to make } \\
\text { a final diagnosis }\end{array}$} & Dentist & 15 & 100 & 0 & 0 & 15 & 100 & \multirow{2}{*}{100} & \multirow{2}{*}{0} \\
\hline & & Radiologist & 9 & 100 & 0 & 0 & 9 & 100 & & \\
\hline \multirow{2}{*}{6} & \multirow{2}{*}{$\begin{array}{l}\text { Statistical reporting capability } \\
\text { of the system }\end{array}$} & Dentist & 7 & 46.7 & 8 & 53.3 & 15 & 100 & \multirow{2}{*}{50} & \multirow{2}{*}{50} \\
\hline & & Radiologist & 5 & 55.6 & 4 & 44.4 & 9 & 100 & & \\
\hline \multirow{2}{*}{7} & \multirow{2}{*}{ Option to take patient turn } & Dentist & 11 & 73.3 & 4 & 26.7 & 15 & 100 & 75 & 25 \\
\hline & & Radiologist & 7 & 77.8 & 2 & 22.2 & 9 & 100 & 15 & 25 \\
\hline 8 & Space to view patient report of & Dentist & 15 & 100 & 0 & 0 & 15 & 100 & 100 & 0 \\
\hline$\gamma$ & diagnosis & Radiologist & 9 & 100 & 0 & 0 & 9 & 100 & 100 & 0 \\
\hline 9 & Space for the secretary to take & Dentist & 14 & 93.3 & 1 & 6.7 & 15 & 100 & 917 & 83 \\
\hline 9 & turns & Radiologist & 8 & 88.9 & 1 & 11.1 & 9 & 100 & 91.1 & 8.3 \\
\hline 10 & Space for consultation (Dentist & Dentist & 10 & 66.7 & 5 & 33.3 & 15 & 100 & 75 & 25 \\
\hline 10 & Questions \& Answers) & Radiologist & 8 & 88.9 & 1 & 11.1 & 9 & 100 & 75 & 25 \\
\hline
\end{tabular}


After the data needs of this system were determined, the conceptual model of the telemedicine consulting system based on the integrated modeling language was plotted as diagrams used, including the diagrams used by the secretary (Fig 1), the dentist (Fig 2), Patient (Fig 3) and radiologist (Fig 4). Which were shown separately.

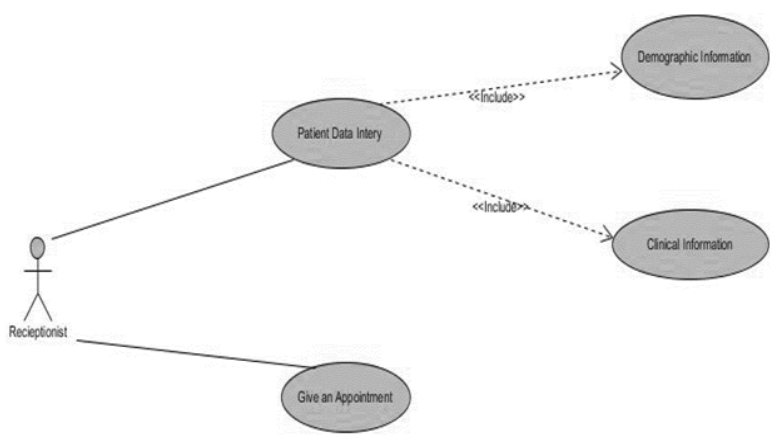

Fig 1: Use case diagram for secretary

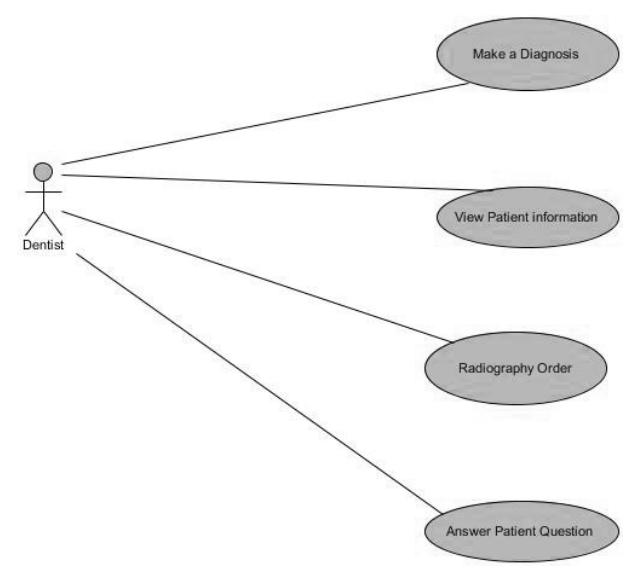

Fig 2: Use case diagram for dentist

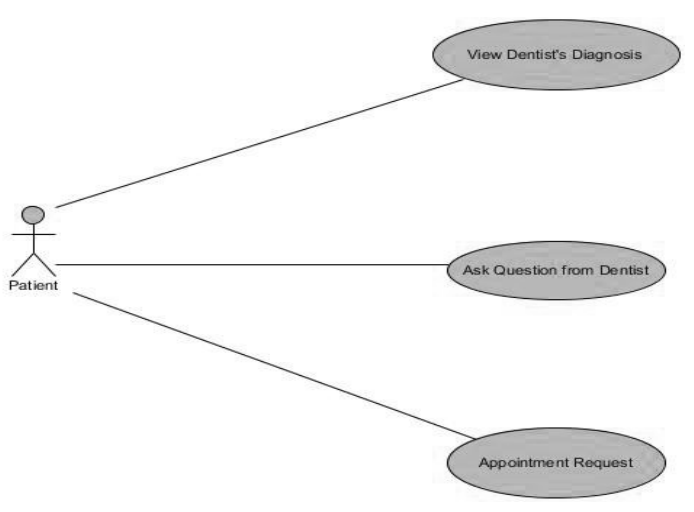

Fig 3: Use case diagram for patient

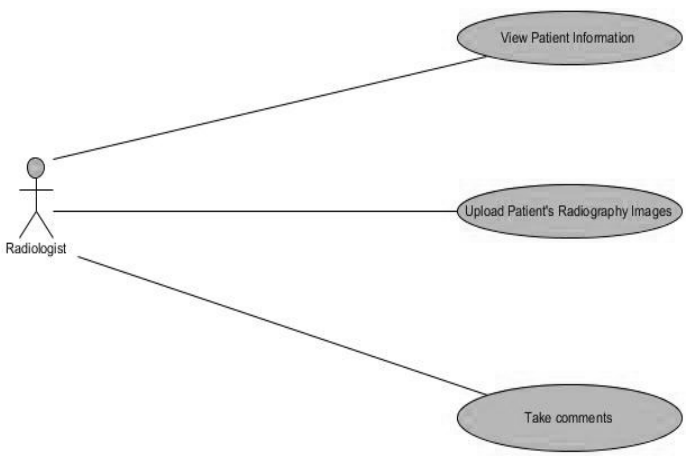

Fig 4: Use case diagram for radiologist

Discussion

In a study by Bradley et al. on the feasibility of presenting a prototype telemedicine program, the minimum patient data needed for teleconsultation by dental practitioners including patient medical information. These included cardiac, vascular, respiratory and thoracic problems as well as possible allergies, and provided specific codes for patient demographic information, as well as imaging and radiographic information including supplementary patient records []].

In Toos et al. study, only patient examination information as well as color images of the lesion in question from 60 patients who needed dental care were sent to two specialists via email to provide diagnosis. In this study, each code was assigned to each patient in order to identify the patient [18]. At the same time, we attempted to incorporate demographic information along with clinical information into our study as independent records for each patient. In another study by Morosini et al. 102 adolescents aged 15 to 19 years were studied. Personal information including demographic information, marital status, level of education, social activity and health information including complaints of dental discomfort, tobacco use and other medications, as well as patient pictures and clinical information were collected along with this information. It was recorded that color images of the teeth were recorded. These images were taken using a quality camera and at least five images were obtained from different angles of the teeth. While the teeth were positioned face to face, two images from the left and right and other images were taken from the surface of the upper and lower jaws of each patient. Patient information, along with the supplementary form, was sent to two distant specialists using the storage and retrieval method. Finally, the results showed that using the camera, the computer and the Internet not only reduced costs but also provided telemedicine services to people living in disadvantaged areas. Also the results of this study showed that it is not different from 
traditional examination [16].

Estai et al. conducted a study to evaluate telemedicine cloud systems for oral diseases. The Australian e-Health Research Center designed an Android-based program to transfer data through storage and retrieval for dental caries assessment and screening. Features include the ability to retrieve and store images from both mobile and computer, as well as take pictures, data entry, storage and retrieval to maintain password security. Each program included relevant code, as well as information such as date of birth, sex, indigenous status, as well as urban or rural residence, including demographic information, as well as storage space for images. It also eliminates the possibility of removing the image and re-imaging, as well as the space where the relevant dentist will remotely comment on each individual dental image. According to the results, the use of mobile applications for telemedicine dentistry with data storage and retrieval is an appropriate solution for screening dental caries rather than in-person examinations [9]. Considering the aforementioned cases, the use of telemedicine in dentistry is a viable and costeffective solution, especially when access to a specialist is difficult and costly, although in some studies using email and digital cameras use the minimum equipment for telemedicine, but the standard and minimum standard equipment have not yet been considered [1]].

\section{CONCLUSION}

Although much research has been done in the field of telemedicine, little has been done on telemedicine and its benefits and applications [18]. The purpose of this study was to determine the data elements needed for telemedicine consulting systems from the perspective of dentists and radiologists. These data elements include demographic and clinical information of the patient and the capabilities that the system should have.

Considering the aforementioned, the use of telemedicine can overcome problems such as unnecessary referrals, the need to travel long distances, unnecessary costs and the prevalence of illness. Implementation of this system in Iran can not only overcome the above mentioned problems but also make it more efficient in dental science.

\section{AUTHOR'S CONTRIBUTION}

All the authors approved the final version of the manuscript.

\section{CONFLICTS OF INTEREST}

The authors declare no conflicts of interest regarding the publication of this study.

\section{FINANCIAL DISCLOSURE}

No financial interests related to the material of this manuscript have been declared.

\section{REFERENCES}

1. Dasgupta A, Deb S. Telemedicine: A new horizon in public health in India. Indian J Community Med. 2008; 33(1): 3-8. PMID: 19966987 DOI: 10.4103/0970-0218.39234 [PubMed]

2. Ayatollahi H, Pourfard Sarabi FZ, Langarizadeh M. Clinicians' knowledge and perception of telemedicine technology. Perspect Health Inf Manag. 2015; 12(Fall): 1c. PMID: 26604872 [PubMed]

3. Wacloff J, Tang JMW. Teledentistry in Arizona: Initial development. Arizona Department of Health Services; 2009.

4. Daniel SJ, Kumar S. Teledentistry: A key component in access to care. J Evid Based Dent Pract. 2014; 14: 201-8. PMID: 24929605 DOI: 10.1016/j.jebdp.2014.02.008 [ubMed]

5. Ahovuo-Saloranta A, Forss H, Walsh T, Hiiri A, Nordblad A, Mäkelä M, et al. Sealants for preventing dental decay in the permanent teeth. Cochrane Database Syst Rev. 2013; 3: CD001830. PMID: 23543512 DOI: 10.1002/14651858.CD001830.pub4 [PubMed]

6. Morosini Ide A, de Oliveira DC, Ferreira F de M, Fraiz FC, Torres-Pereira CC. Performance of distant diagnosis of dental caries by teledentistry in juvenile offenders. Telemed J E Health. 2014; 20(6): 584-9. PMID: 24693859 DOI: $10.1089 /$ tmj.2013.0202 [PubMed]

7. Fricton J, Chen H. Using teledentistry to improve access to dental care for the underserved. Dent Clin North Am. 2009; 53(3): 537-48. PMID: 19482128 DOI: 10.1016/j.cden.2009.03.005 [PubMed]

8. Mariño R, Marwaha $\mathrm{P}$, Collmann R, Hopcraft $\mathrm{M}$, Manton D, McCullough $\mathrm{M}$, et al. Field testing of remote teledentistry technology. The Sixth International Conference on eHealth, Telemedicine, and Social Medicine; 2014.

9. Hosseinpour R, Safari H. A review of statistics and information in dentistry. Iranian Dental Association: Tehran; 2013.

10. Torres-Pereira CC, Morosini I de Ac, Fonseca BB. Teledentistry and the distant diagnosis of oral mucosal disease. In: Kumar S (ed). Teledentistry. Springer; 2015.

11. Ozkan Ata S, Ozkan S. Information technology in oral health care: Attitudes of dental professionals on the use of teledentistry in Turkey. Eur Mediterranean Conf Information System; 2009.

12. Estai M, Kanagasingam $Y$, Xiao D, Vignarajan J, Huang B, Kruger E, et al. A proof-of-concept evaluation of a cloud-based store-and-forward telemedicine app for screening for oral diseases. J Telemed Telecare. 2016; 22(6): 319-25. PMID: 26377126 DOI: 


\subsection{7/1357633X15604554 [PubMed]}

13. Baheti MJ, Bagrecha SD, Toshniwal NG, Misal A. Teledentistry: A need of the era. Int J Dent Med Res. 2014; 1(2): 80-91.

14. Mariño R, Clarke K, Manton DJ, Stranieri A, Collmann $\mathrm{R}$, Kellet $\mathrm{H}$, et al. Teleconsultation and telediagnosis for oral health assessment: An Australian perspective. In: Kumar S (ed). Teledentistry. Springer; 2015.

15. Mahdizadeh H. Creation of teledermatology system in nursing home. [MSc thesis] Iran University of Medical Sciences; 2012.

16. Hassannejad M. Developing a web-based system for self-care management of type 1 diabetes. [MSc Thesis] Iran University of Medical Sciences; 2013.

17. Torres-Pereira CC, Morosini I de A, Possebon RS, Giovanini AF, Bortoluzzi MC, Leao JC, et al. Teledentistry: Distant diagnosis of oral disease using e-mails. Telemed J E Health. 2013; 19(2): 117-21. PMID: 23356381 DOI: $10.1089 /$ tmj.2012.0087 [PubMed]

18. Bradley M, Black P, Noble S, Thompson R, Lamey PJ. Application of teledentistry in oral medicine in a community dental service, $\mathrm{N}$. Ireland. $\mathrm{Br}$ Dent J. 2010; 209(8): 399-404. PMID: 20966999 DOI: 10.1038/sj.bdj.2010.928 [PubMed] 